\title{
(accepted) Cognitive regulation outdoes behavior regulation in predicting state standardized test scores over time
}

\author{
Anahid S. Modrek ${ }^{1} \&$ Gerardo Ramirez ${ }^{2}$ \\ ${ }^{1}$ Department of Psychology, Thomas Jefferson University \\ ${ }^{2}$ Department of Educational Psychology, Ball State University
}

PAPER ACCEPTED IN Metacognition and Learning

Citation:

Modrek, A. S., Ramirez, G. (accepted) Cognitive regulation outdoes behavior regulation in predicting state standardized test scores over time. Metacognition and Learning.

Correspondence should be directed to:

Anahid S. Modrek, Ph.D.

Assistant Professor

Department of Psychology

Thomas Jefferson University

Downs Hall, Office 24,

4201 Henry Avenue,

Philadelphia, PA 19144

anahid.modrek@jefferson.edu |p: 215-898-7300 / f: 215-573-3226

www.anahidmodrek.com 


\section{Compliance with Ethical Standards}

The authors declare that they have no conflict of interest. The rights of the participants were

protected, and applicable human research subject guidelines were followed in this research. All participants provided informed consent. 


\begin{abstract}
Individual differences in self-regulation have been a topic of increased empirical research. However, few investigations have been conducted on how sub-components of self-regulation differentially predict education outcomes over time. We examined cognitive and behavior regulation as predictors of middle-school students' $(n=127)$ long-term academic achievement. It has been previously reported that behavior regulation, not cognitive regulation, predicts state standardized test scores in the first year (Modrek et al., 2019). However, here we show that after two years, this pattern flips in that cognitive regulation, not behavior regulation, predicts state standardized test scores for both math and English. We analyzed the mediating role of learning using structural equation modeling, suggesting the differing roles of self-regulation in education where certain facets may or may not affect students' long-term outcomes.
\end{abstract}

Keywords: long-term achievement, cognitive regulation, learning, math, individual differences, 
Students' self-regulation skills in the classroom are an important lens to understand individual differences in students' learning and academic achievement. Self-regulation refers to the process by which individuals control their thoughts and actions to meet their goals as well as the demands of the surrounding environment (Baumeister et al., 1994; Carver \& Scheier, 2004). Self-regulation skills are a critical predictor of health, well-being, and many educational outcomes (McClelland et al., 2018). Despite increased interest in the study of self-regulation, understanding how subsets of self-regulation differentially predict outcomes over time remains limited. The structure and different functions of self-regulation may be specific to adolescence, constituting a sensitive period in development that warrants further investigation (Blair \& Razza, 2007; Burrage et al., 2008; McClelland et al., 2018). In the current study, we explored which facets of self-regulation predict learning and academic outcomes across two years. Identifying the self-regulatory predictors of learning and long-term academic achievement will provide insight into specific skills that teachers and parents should help the students develop to reap the benefits of their educational opportunities.

Students spend most of their day in classrooms where they receive long periods of instruction and are tasked with completing challenging and often uninteresting tasks that require them to regulate themselves from external distractors (i.e., laptops, social media, classmates; Fried, 2008; Junco, 2012; Wood et al., 2012) as well as internal distractors (i.e., mind wandering and leisure relevant thought; Inzlight \& Schmeichel, 2016; Lindquist \& McLean, 2011; Risko et al., 2012; Unsworth et al., 2012). To be successful in school, students need to be willing and capable to manage their thoughts and behaviors in the classroom. Self-regulation is fundamental to learning (Corno \& Mandinach, 1983), academic performance (Blair \& Diamond, 2008), and broader educational trajectories (Bandura et al., 2001; Blair et al., 2015; Corno \& Rohrkemper, 1985; Geldhof et al., 2010; Prencipe et al., 2011). 
Several important debates and inconsistencies exist within the literature, including the lack of integrated self-regulation studies across the life span (McClelland et al., 2018). Other studies highlight the conceptual overlap between self-regulation and other distinct constructs such as executive function, delay of gratification, intelligence, working memory, and effortful control (Duckworth \& Kern, 2011; Duckworth \& Seligman, 2005; Duckworth et al., 2010; McClelland et al., 2018; Milyavskaya et al., 2019). Self-regulation constructs certainly suffer from a jingle-jangle fallacy where researchers use different terms to potentially describe the same construct (Duckworth et al., 2012; Thorndike, 1904).

Another debate concerns whether self-regulation is best characterized as a unitary or multidimensional construct (Kaplan, Middleton, Urdan, \& Midgley, 2002; Sameroff, 2010; BenEliyahu, 2019). Our view aligns with the evidence demonstrating that students' performance on various self-regulation skills predicts different sets of outcomes differentially (Duckworth et al., 2012; Kim et al., 2013). Indeed, research using confirmatory factor analysis has supported a multidimensional structure of self-regulation (Brock et al., 2009; Willoughby et al., 2011). The field has not reached a consensus on several important debates within the self-regulation literature, including the uni- versus multi-dimensionality of self-regulation ( $\mathrm{Li}$ et al., 2011; Zimmerman, 2008). However, three basic forms of self-regulation that deal with students' ability to regulate their emotions, behaviors, and cognitions have been widely considered (Ben-Eliyahu \& Linnenbrink-Garcia, 2015; Duckworth \& Seligman, 2005; Duckworth et al., 2010; McClelland et al., 2018).

Works from clinical, cognitive, and social psychology highlight the importance of emotion self-regulation, i.e., the ability to modulate, change, and properly appraise strong emotional reactions with appropriate and flexible strategies (Graham, \& Taylor, 2014; Gross, 1998; Gross, 2008; Weiner, 1985; Wilson, \& Buttrick, 2016). Students must, for example, be 
able to maintain task engagement when hungry (Shoda et al., 1990), anxious (Cisler et al., 2010; Smith et al., 2018), and frustrated (Meindl, Yu, Galla, Quirk, Haeck, Goyer, Lejuez, D’Mello, \& Duckworth, 2019), among other affective experiences that are common in classrooms. While emotion self-regulation is an important construct within the self-regulation literature, in this study, we focused on the differences between behavioral self-regulation and cognitive selfregulation, which we now address.

The study of self-regulated behaviors emphasizes observable behaviors that demonstrate self-control. In the classroom, assessments of self-regulated behavior include measures of both students' on- and off-task behavior (D'Mello et al., 2017; Ponitz et al., 2008). Identifying on-task versus off-task behaviors has been accepted as one mechanism to assess a part of behavior regulation skills. On-task behavior refers to students actively engaging in activities instructed by the teacher, such as working on a classroom assignment or following a teacher's lecture. At the same time, off-task behavior involves disengagement from the instructed activity (such as socializing with their peers while being instructed to work on curriculum) and channeling efforts elsewhere (Chafouleas et al., 2010; Moffett \& Morrison, 2020).

Cognitive self-regulation refers to cognitive functions that allow individuals to monitor and manage their thoughts. Cognitive self-regulation and executive functions (EF) are similar but distinguishable (Miyake \& Friedman, 2012), with executive functioning being a broader construct. Cognitive self-regulation is mostly driven by control of thought (Hasher et al., 1999). The consensus of which skills and processes constitute cognitive regulation varies across studies (Miyake \& Friedman, 2012; Xu et al., 2013; Zhou, Chen, \& Main, 2012); yet, research has identified only a few key cognitive regulatory skills, such as inhibition and switching (McClelland et al., 2000). Inhibition refers to the cognitive ability to suppress task-irrelevant information and restrain an impulsive response, such as disregarding a distracting thought when 
trying to solve a math problem (Miyake et al., 2000). Inhibition develops throughout childhood (e.g., Jones et al., 2003) and into early adulthood (e.g., Hooper et al., 2004). Switching refers to the cognitive ability to change between tasks effectively. Recent studies have suggested that switching and inhibition, as well as other cognitive regulation components, predict academic performance in distinct ways and across different domains (Blair \& Razza, 2007; Kuhn \& Pease, 2009; Latzman et al., 2010).

While certain executive functioning skills (such as shifting and inhibition) sub-serve cognitive self-regulation (Hofmann et al., 2012), in some studies, different executive functions were correlated, thus tapping into some common dimension (unity), while in other studies, they showed some divergence (diversity) (Miyake \& Friedman, 2012). For example, some studies have found inhibition to be positively associated with switching (Bull \& Scerif, 2001), while other studies have found them to have significant amounts of non-shared variance (Miyake et al., 2000). Inhibition (Miyake et al., 2000) as well as switching (Heaton et al., 1993) account for commonality between different executive functions, as a broader executive and cognitive selfregulatory functions require some form of inhibitory and switching skill to take effect. Having such skills allows for switching between tasks and attention, especially in multifaceted learning environments such as classrooms.

In sum, empirical studies that have simultaneously investigated cognitive and behavioral self-regulation processes as predictors of educational outcomes have found enough non-shared variance between the two, warranting their treatment as distinct constructs (Duckworth \& Seligman, 2005; Duckworth et al., 2010; Linnenbrink \& Pintrich, 2000). An important issue that remains unanswered is whether cognitive and behavioral self-regulation predicts academic performance similarly or differentially in short- versus long-term. Some findings suggest cognitive skills are more predictive of later achievement compared to general behaviors (Barriga 
et al., 2002; Frick et al.; Hinshaw, 1992; Kim et al., 2020; Konold \& Pianta, 2005; Trzesniewski et al., 2006). Other work has found that skills guiding cognitive self-regulation are significant predictors of long-term achievement (Claessens et al., 2009; Duncan et al., 2007; Watts et al., 2014) while some research has reported that behavioral self-regulation predicts long-term classroom outcomes (Duckworth et al., 2012; Duckworth \& Seligman, 2005). Examining cognitive self-regulation separately from behavioral self-regulation is crucial because each factor may predict a different set of outcomes both in the short and long term (Bailey et al., 2017; Carrell \& West, 2010; Stroebe, 2016).

Our first research question asks: How do different facets of self-regulation among adolescents predict learning and academic outcomes within one year as well as long-term academic outcomes in year 2? We begin by reiterating previous findings (Modrek, Kuhn, Conway, Arvidsson, 2019), which showed that behavioral but not cognitive self-regulation directly predicted academic performance assessed within year 1 of the same academic year (i.e., performance on state standardized tests). We then go beyond previous work by testing whether behavior and cognitive self-regulation differentially predict academic performance on state standardized exams the following year after covarying out year 1 exam performance. We predicted that in year 2 , the relationship would switch in that cognitive but not behavioral selfregulation will predict year 2 academic performance after covarying out year 1 performance (Hypothesis 1).

We surmised that students' ability to follow instructions, come to class, and stay on-task and other activities would relate to behavioral regulation, which is an important skill that predicts how well they will perform on standardized tests during observable year 1 . By contrast, cognitive self-regulation skills may be more pronounced within outcomes that require understanding, reasoning, and critical thinking, that is, skills that are more generally required for sustained, 
long-term learning. We operationalized long-term learning by examining how well students score on long-term standardized tests after covarying outperformance on short-term standardized test scores (Laird et al., 2005).

Examining long-term achievement skills (after covarying out baseline achievement) is arguably a finer measure of long-term learning effectiveness. The goal of education is for students to showcase higher-order thinking skills that go beyond the skills needed to perform on immediate standardized exams (Modrek et al., 2019; Modrek \& Kuhn, 2017; Braga et al., 2014; Carrell \& West, 2010; Yunker \& Yunker, 2003). Activities that promote better encoding show greater benefits on far rather than near transfer outcomes (Soderstrom \& Bjork, 2015). Similarly, students who participate in courses with more rigorous instructors perform slightly worse in their initial courses but perform better in subsequent courses (Braga et al., 2014; Carrell \& West, 2010; Kornell \& Hausman, 2018). Hence, we predicted that cognitive (but not behavioral) selfregulation would show greater predictive power for performance on long-term standardized test assessed by academic achievement over 2 years.

Similarly, we set out to test an indirect path between cognitive regulation and year 2 achievement through inquiry learning. Inquiry learning entails self-directed knowledge acquisition, ideally in a way that parallels the way scientists study the world. The inquiry is a specific type of learning that gives priority to self-directed exploration and investigation and to inferences justified by newly found evidence, rather than focusing on prior beliefs (Wilson et al., 2010) or committing to memory of information conveyed (de Jong \& van Joolingen, 1998). Inductive reasoning, a major component of inquiry learning, is the process by which individuals will revise their prior beliefs based on newly found evidence and draw new causal conclusions from that new information (Holland et al., 1989). Previous work has demonstrated that cognitive regulation relates to immediate learning and reasoning effectiveness (Blair \& Raver, 2014), and 
research on inductive reasoning reveals that such skills relate to students' inquiry learning ability (see Kuhn \& Pease, 2009). We suggested that student's inductive reasoning and inquiry learning may scaffold the type of higher-order thinking processes that lead to deep and sustained learning over time (Kuhn \& Pease, 2009; Soderstrom \& Bjork, 2015). If this were the case, then we posited that cognitive but not behavioral regulation would relate to state standardized test performance indirectly through inquiry learning ability for both year 1 and year 2 scores (Hypothesis 2).

We evaluated the hypotheses above across the math and English domains. Both behavioral and cognitive regulation strategies have many facets. Some have been found to predict math skills, while others predict English reading skills (Latzman et al., 2010). Previous studies have demonstrated a relationship between cognitive regulatory processes and math (Blair \& Razza, 2007; Bull \& Scerif, 2001; Espy et al., 2004). For example, inhibition at age six was found to be related to performance on two standardized math assessments, both concurrently and over three subsequent years, suggesting moderate stability in the relation between cognitive regulatory processes and math performance (Mazzocco \& Kover, 2007). Especially in adolescence, little has been done to compare the predictors of math and English (Bodovski \& Farkas, 2007; McGlamery et al., 2007; Rigas et al., 2002). Thus, we tested our conceptual model on both math and English scores across two years to understand how they may differentially predict the relationships outlined in Hypotheses 1 and 2.

We focused our investigation on adolescence, a period that requires a high degree of selfregulation as students engage in more novel and sensation-seeking behaviors (DoremusFitzwater et al., 2010; Sturman \& Moghaddam, 2011) and attempt to negotiate competing interests and identities against their increased autonomy over their responsibilities as students (Brown, 2004; Brown \& Larson, 2009; Laursen \& Collins, 2009). Adolescence is also a period 
when students face the highest demands to cover content from their teachers, while interest and achievement tend to decline (Osborne et al., 2003). Compared to younger children, adolescents are cognitively and developmentally more able to take on a high level of independence and personal control (Pintrich \& Schunk, 2002). Often, however, opportunities for adolescents to develop autonomy and exercise self-regulation within the classroom are lacking (Feldlaufer, Midgley, \& Eccles, 1988; Kuhn, Modrek, \& Sandoval, 2020). When adolescents are offered fewer choices and fewer opportunities to assume personal responsibility and more autonomy, it can affect not only their reasoning skill (Modrek \& Sandoval, 2020; Modrek, in press) but also the development of self-defeating motivational beliefs (Eccles et al., 1993). Adolescents must resist a wide range of temptations. Some of these temptations (i.e., staying in your seat and on the task rather than socializing or going on social media) portray behavior regulation (Mendl et al., 2019) while other temptations (i.e., analyzing a complex problem while avoiding ruminations) require cognitive regulation. Hence, we address sub-components of self-regulation that might best predict the year 1 and year 2 academic performance as well as inquiry learning during a critical period when self-regulation is a key asset.

\section{Methods}

\subsection{Data \& Design}

Data for this project was collected as a part of a larger project examining self-regulation skills and individual differences in reasoning and learning effectiveness (Modrek et al., 2019). Some of the data for year 1 have been reported in a previously published study (Modrek et al., 2019). The current study builds on the work of Modrek and colleagues (2019) by examining the self-regulation components that predict longitudinal state standardized achievement scores directly over 2 years. Another novel aspect of this study is our focus on the relationship of selfregulation skills on academic performance in year 1, and long-term achievement (year 2) data 
through inductive reasoning using a structural equation modeling approach. The study used a longitudinal design, where participants were followed across two academic years. A previous study (Modrek et al., 2019) did not (a) analyze the mediating role of inquiry learning between self-regulatory constructs and achievement (rather, we showed direct associations between selfregulatory constructs and either learning or achievement), and (b) have longitudinal data to conduct further SEM analyses of academic achievement scores in year 2. The sponsoring university's institutional review board and the school district approved the study procedures and data collection. The rights of the participants were protected, and applicable human research subject guidelines were followed in this research.

\subsection{Participants}

Participants were 135 middle-class students in $5^{\text {th }}$ and $6^{\text {th }}$ grade who were followed through $6^{\text {th }}$ and $7^{\text {th }}$-grade, respectively $(55 \%$ female; age $\mathrm{M}=11.3$, range $10-12, \mathrm{SD}=0.67)$. Participants were students at a public middle school in a largely working-class neighborhood of a large city in the Northeast US and came from a broad range of backgrounds. Three 6th grade and two 5 th grade classrooms were included, totaling five classes. Each class had approximately 27 students. Both 5th grade classes had the same teacher, and the three 6th grade classes also had the same teacher. The sample comprised $52 \%$ of Caucasians, $12 \%$ of Asians, $10 \%$ of AfricanAmericans, $7 \%$ of Hispanics, and $19 \%$ of mixed background. Over half of the sample (56\%) was bilingual (most common languages spoken included Russian, Hebrew, Italian, Greek, and Mandarin). According to the state department of education (DOE) data, the school's performance ranking was in the 47 th percentile, making this an academically typical site for addressing our research questions. Approximately $10 \%$ of students qualified for free or reduced-price lunch. School administration and teachers confirmed that students had not previously engaged in inquiry activities nor ones involving collaborative thinking. All participants' parents signed 
consent forms permitting researchers to access test performance records. State proficiency rating scores were utilized for longitudinal analyses. Due to attrition, we had 8 fewer students in year 2 . Thus, the original sample of 135 during the first year was reduced to a sample of 127 in the second year.

\subsection{Measures}

\subsubsection{Behavior Regulation}

An assessment of behavior regulation was based on classroom observation and was conducted under normal classroom conditions. Behavior regulation was assessed using the Baker-Rodrigo Observation Method Protocol (BROMP; Ocumpaugh, 2012). This task has been widely used in the educational studies of learning, engagement, and data mining (D'Mello et al., 2017; Ocumpaugh et al., 2012; Ocumpaugh et al., 2014; Ocumpaugh et al., 2015), and it has been empirically established as a measure of behavior regulation for both age groups being observed (Chafouleas et al., 2010) as well as younger students (Moffett \& Morrison, 2020). The BROMP coded students' on-task or off-task behaviors into fixed and randomized time segments. The coder (the first author in the present study) was BROMP- certified, having achieved interrater reliability of 0.6 or higher with another BROMP- certified coder on a minimum of 200 separate observations.

Observations were conducted using a handheld Android app, HART, designed for this purpose (Ocumpaugh, 2012). Students were unaware of when they were being observed as a part of the BROMP. To balance observations and avoid biased behaviors, they were randomly but equally dispersed and conducted in a predetermined order. The coder did not have any additional interactions with students before BROMP coding. Total observation period was approximately 2 hours, during which students were randomly and equally observed a total of 12 times. The first 
behavior displayed by the students within 20 seconds of the beginning of the observation was coded. Each observed segment was coded as one of the following:

1) On-task behavior-student was working on the subject material presented by the teacher.

2) On-task conversation- student was engaging in an appropriate conversation with either the teacher or another student about the subject material.

3) Off-task behavior- student behavior was relevant to not task or subject (e.g., playing with a personal possession such as cell phone).

4) Other-student was either out of his/her seat or temporarily out of class and unable to be coded. (These segments were excluded from analyses.)

5) Total Behavior Regulation score - Each student's total behavior regulation score was calculated by subtracting the number of off-task segments from student's ontask segments [On task - off task]. This was used as our primary measure of behavior regulation.

\subsubsection{Cognitive Regulation}

We used the Shape School task (Espy, 1997) to assess cognitive regulation. This task was originally designed for younger children, and it has repeatedly demonstrated satisfactory reliability and validity in previous research, with an average Cronbach's alpha of .70 (Espy et al., 2006; Espy et al., 1999; Ganesalingam et al., 2011). In our study, the Cronbach's alpha was .67. The task was later adapted for young adults (Chevalier et al., 2013) and adolescents (see Modrek et al., 2019), which is what we used here. The task was presented verbally as well as in a paper booklet form and administered by the first author individually. Participants were required to respond out loud. The task took, on average, 15 minutes to complete. 
The shape school task assesses different aspects of cognitive regulation using colorful, effectively engaging stimuli presented in an appealing story-book format. It contains four parts. During the first baseline task (Task A), participants were simultaneously presented with three rows of five figures. The figures were presented randomly in one of four different colors and one of three different shapes. During task A, participants were asked to name the color of each of the 15 figures, starting from the top left figure to the bottom right figure. Participants were given a score based on the number of correct responses. The inhibition task (Task B) presented participants with the same three rows of five figures, except that now nine of the figures had happy faces, and six had sad faces, which were also randomly distributed. The participants were instructed to call out only the colors of figures with happy faces, which required response inhibition for the sad faces. Participants were given a score based on the correct number of figures with happy faces they were able to identify. In the switching task (Task C), seven of the figures were now wearing hats, and eight were without hats (happy/sad faces were absent for this specific task). The figures were once again presented randomly in three lines of five each. The participants were told that when they came to a figure wearing a hat, they should respond by saying the shape of the figure. However, when they come across a figure not wearing a hat, they should respond by identifying the color. Participants were given a score based on the correct number of shape names given to hat-wearing figures in addition to the correct number of color names given to figures without hats.

Finally, during the switching and inhibition task (Task D), a final set of 15 figures varied in facial expressions, showing a "happy/sad" face, and in wearing/not wearing hats. Participants were instructed to refrain from naming the "sad" figures (names were either colors or shape, contingent upon whether they had a hat on). Participants were also instructed to name the "happy" figures regardless of whether they were wearing a hat. Five figures were happy and 
without hats, three figures were happy and with hats, three were unhappy and had hats, and four were unhappy without hats. Participants were given a score based on the correct number of shape names they gave to hat-wearing figures in addition to the correct number of color names they gave to figures without hats, but only for the happy figures.

On all four tasks, participants were assigned a score based on the number of correct responses. We used participants' performance on the combined switching and inhibition task (Task D), as a previous study (Espy et al., 2006), as well as our study, revealed that it produces greater variability. The maximum possible score for the combined switching and inhibition (Task D) was 8 .

\subsubsection{Inquiry Learning}

The inquiry learning task required participants to independently examine a dataset consisting of cases that varied on multiple dimensions and to discern causal relations characterizing the dataset. This task has been widely used in studies investigating inquiry learning skills, causal learning, and inductive inference (Chinn, \& Malhotra, 2002; Dean \& Kuhn, 2007; Holyoak \& Cheng, 2011; Kuhn \& Pease, 2008), as well as problem-solving (Greiff et al., 2013). It has been used with both adults as well as with children and has been demonstrated as a valid and reliable task (Kuhn et al., 2015; Schauble, 1990; Sobel \& Munro, 2009; Modrek et al., 2019). The task was administered individually to each participant and required, on average, 60 minutes to complete. We briefly summarize the task below. A full copy of the procedure and instructions can be found in Modrek et al., 2019.

The inquiry learning task consisted of an introduction, learning phase, and application phase (each outlined below). During the introduction phase, participants were introduced to a scenario describing a new space foundation that wants to select astronauts for a new space station. Participants were then told the space foundation was considering four factors that might 
make a difference in how well potential astronauts may perform while living on a space station: fitness, family size, education, and parents' health. Participants were asked to hypothesize, on a hypothesis card, about which of the four factors they think would make a difference. After the participants made their hypotheses about which factors would be predictive, they turned in their hypothesis card to the experimenter. They were then given data and records about how the trial astronauts did in the simulator during the learning phase in which participants were required to reason about the data inductively.

The learning phase began with the interviewer presenting participants with a blank summary sheet of the four factors. Participants were invited to choose one of the factors for further study (i.e., family size). They were then presented with several previous case studies of trial astronauts, each containing information regarding the applicant's status concerning the four factors. Participants were invited to reason inductively when assessing these case studies and choose two case studies to study more closely before being shown the performance outcomes for the applicant described in the case study. The interviewer invited but did not require the participant to conclude whether the factors being investigated on the cards made a difference. For instance, a participant may have asked to begin the learning phase by closely examining the family size factor. The participant might have then chosen case study \#19 and \#3 to study for a short period and notice that both applicants have a small family size before the experimenter wrote down the performance for both applications (i.e., poor and so-so). In the example being described, the participant might have reasons that family size (at least in these two examples) does not seem to make much of a difference in performance. For family size, participants were prompted with the question, "Does the size of the family in which the person grew up matter?" This procedure was designed to encourage participants to draw an inference about the efficacy of the factor being investigated. This procedure continued until students felt satisfied with their 
inferences about the efficacy of the specific factor. This procedure was then repeated for all four factors until students felt satisfied with their level of inquiry. By the end of the learning phase, participants had a completed summary sheet that indicated their overall inferences about all four factors.

During the application phase, participants were allowed to apply what they learned as they evaluated new applicants. Participants were presented with the profile of 10 potential astronauts whom the foundation was seriously considering and asked to predict their performance. Participants were allowed to hold on to and use their completed summary sheet (to control for their initial findings). Participants were presented with the case study of each new astronaut (outlining their fitness, parent health, family size, and education) one at a time and asked to indicate, "How well do you think this applicant will perform" on a 5 point scale (very well, well, so, poorly, very poorly). This method allowed us to measure the extent to which students relied on inductive reasoning based on recent learning experiences as opposed to initial hypotheses based on pre-existing ideas (all the while controlling for memory skill by not requiring the participants to remember what they found but to refer to their summary sheet).

The learning and application phases of the task were scored separately. For the learning phase, participants received a score for the correctness of the conclusion drawn about each of the four variables. Each variable was assigned a score between 0 and 4 . Total scores for this portion ranged from 0 to 16 . In the application phase, scores were based on the correctness of each of the 10 predictions for new applicants, ranging from 0 to 4 . Points were taken away from the maximum (of 4) according to how far away the prediction was from the correct selection. Adjacent selections received 3 points, with each additional space away from the correct selection losing 1 more point. Across the ten total predictions made, scores ranged from 0 to 40 . To compare the effectiveness of the learning and application phases, learning phase scores were 
subsequently transformed into a distribution having the same range as the application scores, 0 40.

\subsubsection{State Standardized Test Scores}

State standardized achievement test scores for both math and English were obtained for all students in our sample. Only math and English standardized achievement test scores were available at the state level for P-12 public schools in this northeastern state. The math test contained multiple-choice and open-response questions measuring students' understanding of mathematical procedures and concepts. Many of the questions were framed within a real-world context that required the application of knowledge. The math test had satisfactory reliability and validity, as assessed by the state DOE, with an average Cronbach's alpha of .81. The English Language Arts test contained multiple-choice questions as well as open-ended questions measuring students' ability to comprehend and analyze text using stories, articles, or poems they listen to or read. The English test has demonstrated satisfactory reliability and validity, as assessed by the state DOE, with an average Cronbach's alpha of .73.

Both tests were designed to assess the P-12 learning standards for the state. Tests were administered in an untimed manner. Licensed and trained state teachers then scored the test grades. Trained teachers who were not affiliated with respective students' schools scored the exams in compliance with the State Education Department policy. Parents signed a form agreeing to release the scores to the research team. An administrator reported test scores in a spreadsheet.

\subsection{Procedure}

Self-regulation measures were taken early in the academic year. Behavior regulation was the first measure taken (before administering the cognitive regulation task) to ensure that the coder was blind to children's cognitive regulation scores or any other task scores. Approximately 
2 months later, we administered the inquiry learning task. Seven months after self-regulation measures were obtained, students took math and English standardized achievement tests (which we refer to as year 1 test scores). Both math and English standardized achievement test scores were again obtained 19 months after the self-regulation scores (which we refer to as year 2 scores). See Figure 1 for an outline of our timeline.

\section{Results}

\subsection{Descriptive Statistics}

Learning scores ranged from 0 to 40 , with a mean of 28 . Overall cognitive regulation ranged from 33 to 47 , with a mean of 44.8 and a standard deviation of 2.12. Regarding the cognitive regulation sub-scores, inhibition ranged from 4 to 9 , with a mean of 8.73 and a standard deviation of .69 , switching ranged from 4 to 15 with a mean of 14.10 and a standard deviation of 1.23, and combination of inhibition and switching ranged from 0 to 8 with a mean of 7.7 and a standard deviation of 1.51 . Overall behavior regulation ranged from -9 to 9 with a mean of 2.19. Concerning the behavior regulation sub-scores, on-task behavior ranged from 0 to 7 with a mean of 2.78 , the on-task conversation ranged from 0 to 8 with a mean of 2.16 , and offtask behavior ranged from 0 to 8 with a mean of 2.46. Participants indeed displayed considerable individual variation. According to the State DOE reports, approximately $80 \%$ of students at this school met state standards for math, and approximately $70 \%$ met state standards for English.

\subsection{Predictors of Year 1 Math Test Scores}

We used a combination of multivariate regressions (see Supplementary Results) and structural equation modeling (SEM) to conduct the main analyses. For SEM analyses, fully saturated models were employed. The saturated model analyses provide a perfect fit to the data (in line with previous methodologies, see Conway, Miller, \& Modrek, 2017). Age differences in math performance were non-significant ( $\mathrm{p}>.05)$. However, english performance was significantly 
correlated with age, with older students doing better in year $1(r=.174, p<.05)$ and year $2(r=.176$, $p<.05)$. Aggregate change in standardized test performance from year 1 to year 2 scores for math $(p<.05)$ or english $(p<.05)$ was non-significant. In all models, we used age, gender, and bilingualism as covariates, as these variables have shown significant association with both the inquiry learning task and year 1 standardized test outcomes (see Modrek et al., 2019). As previously reported in Modrek and colleagues (2019), behavior regulation and cognitive regulation were significantly associated. However, behavior regulation, but not cognitive regulation, predicted performance on year 1 math test $(B=7.05, p<.001$, and $B=1.27, p=.264$, respectively). We also previously reported that cognitive regulation, rather than behavioral regulation, predicted students' performance on the inquiry learning task, $B=0.985, p<.05$ (see Modrek et al., 2019).

Extending previous work, we used structural equation modeling (SEM) to estimate fully saturated models in our path analyses. The model provided a perfect fit to the data. Our models controlled for age, gender, and concurrent time scores (respectively). Likewise, we tested the restricted maximum likelihood (REML) approach as a form of maximum likelihood estimation that does not base estimates on a maximum likelihood fit of all the information but instead uses a likelihood function calculated from a transformed set of data.

First, with SEM we found an indirect path from cognitive regulation to year 1 math achievement scores (see Figure 2) through inquiry learning (beta range $=.549$ to $2.99, p \leq 0.001$, shown in Table 1). For behavior regulation, with SEM we did not find evidence of an indirect path to year 1 math test scores through inquiry learning. Hence, while cognitive regulation did not show a direct association with year 1 math test scores, the cognitive regulatory skills of an effective learner may have, in turn, resulted in learning outcomes that affect math test 
performance. We now describe how year 1 self-regulation components and the inquiry learning task predicted year 2 math achievement.

\subsection{Predictors of Year 2 Math Achievement}

With SEM we found a direct path from cognitive regulation $(B=.063, p<.001)$, but not behavior regulation ( $B=-.017, p=.669$ ), to year 2 math achievement (see Figure 2). We also found that the inquiry learning task predicted year 2 math achievement, $B=.025, \mathrm{R}^{2}=.232$, $(p<.001)$. The SEM indirect path from cognitive regulation to year 2 math achievement through inquiry learning was significant (beta range: .549 to $2.99, p<.001$ ), whereas the indirect path from behavior regulation was not significant $(p=.704)$. Please see supplementary results for more information on how the various subcomponents of behavior regulation, cognitive regulation, and inquiry learning predicted year 2 math and English outcomes (Supplementary Table S1; S2; S3).

[insert Table 1]

[insert Figure 2]

\subsection{Predictors of Year 1 English Achievement}

We employed the same analytic approach to english year 1 test scores as described earlier. As previously reported (Modrek et al., 2019), neither cognitive regulation $(p=.775)$ nor behavior regulation $(p=.612)$ showed a significant association with year 1 English test scores. We extend previous findings by reporting SEM results, which showed an indirect path between cognitive regulation and year 1 English test scores (see Figure 3) through inquiry learning (beta range $=-.116$ to $.018, p<0.001$; shown in Table 2 ). We did not find evidence for an indirect path between behavior regulation and year 1 English test scores through inquiry learning $(p=.300)$. Hence, the cognitive regulatory skills of an effective learner may, in turn, affect year 1 English test performance. We now describe how self-regulation components and the inquiry learning task predict English achievement in year 2. 


\subsection{Predictors of Year 2 English Achievement}

In contrast to our findings on math, we found no direct association between cognitive regulation $(p=.118)$, or behavior regulation $(p=.403)$, and year 2 English achievement (after controlling for age, gender, bilingualism, and year 1 English scores). We did, however, find that inquiry learning predicted year 2 English achievement in year $2, B=.011, \mathrm{R}^{2}=.514(p<.01)$, (see Table S3 in the supplementary material). Interestingly, we also found that cognitive regulation showed an indirect path ( $\mathrm{p}<.05$; see supplemental material) to year 2 English achievement (shown in Figure 3 ) through inquiry learning (beta range $=.532$ to $.789, p<0.001$; see Table 2 ). The indirect path from behavior regulation to year 2 English achievement through inquiry learning was not significant, $p=.300$ (consistent with what we report for math).

[insert Table 2]

[insert Figure 3]

\section{Discussion}

The self-regulation skills children bring into the classroom have been identified as critically important for ensuring overall academic success. In the current study, we asked about the specific type of self-regulation skills that predict achievement on standardized tests over two years. Our results are broadly consistent with the existing consensus that self-regulation has longitudinal benefits on education outcomes. However, our results revealed a different pattern of results for cognitive versus behavioral regulation.

For math scores, behavior regulation was found to be a predictor of year 1 math achievement but not of year 2 math achievement. Behavior regulation was unrelated to inquiry learning nor indirectly to both years 1 or year 2 math achievement through inquiry learning. In 
terms of cognitive regulation, we found a more nuanced and interesting set of results. Cognitive regulatory skills did not directly predict year 1 math achievement but predicted year 2 math achievement. However, we found that cognitive regulation skills not only predicted performance on the inquiry learning task but additionally predicted indirectly both year 1 and year 2 math achievement through inquiry learning. These results suggest that cognitive regulation has various entry points by which it predicts (and potentially contributes to) students' year 2 math achievement.

It is important to distinguish between our performance outcomes of year 1 and year 2 achievement. While both performance outcomes were based on state standardized exams, our analytic framework defined a high score differently. To perform well on achievement in the first year, students had to demonstrate the ability to readily retrieve the materials which are subject to a host of structural and classroom issues, including teaching to the test, drilling with workbooks, or administering practice tests (Shepard \& Smith, 1990). Teaching to perform well on state standardized tests erodes the specific inferences we can make about performance on these tests, as teachers tend to overemphasize basic-skills and neglect high-order thinking skills (Herman, 1992; Sacks, 2000). To this end, behavior regulation, that is, being able to follow directions, stay on task, and do what an instructor says, may predict academic achievement within one year in that it primarily draws on shallow representation and basic skills that do not necessarily relate to learning (Shepard, 2000; Smith \& Fey, 2000). How well a student performs on a test yielding immediate, observable outcomes requires less understanding, reasoning, and critical thinking (Laird, Shoup, \& Kuh, 2005).

In a sense, our SEM for year 2 achievement is a value-added model that asks what additional value does cognitive versus behavioral regulation adds to explain variation in year 2 achievement once we covaried out variation in the year 1 achievement test. Cognitive but not 
behavioral regulation predicted year 2 achievement scores, suggesting that cognitive regulation predicts greater skill above and beyond what year 1 achievement contributes. The finding further reinforces this interpretation that cognitive regulation is related to inquiry learning and also predicts year 2 achievement through inquiry learning.

For english scores, a direct path from behavior regulation to year 1 or year 2 English achievement was not significant. Using structural equation modeling, however, we found a significant indirect path from cognitive regulation (but not behavior regulation) to year 1 and year 2 english achievement through inquiry learning. Math and english performance have been found to stem from different self-regulatory skills. Latzman and colleagues (2010), for example, found that inhibition (a component of cognitive regulation) persistently predicts math but not English performance. By contrast, cognitive flexibility over new concepts (another component of cognitive regulation) was predictive of English but not math performance.

In sum, cognitive regulation outperforms behavior regulation in predicting both math and English state standardized test scores over time. Our findings showed that inquiry learning is an important factor in the relationship between cognitive regulation and achievement in 1 year as well as an achievement over two years. Why might this be the case? Cognitive regulation over reflexive or instinctive thoughts allows one to rationally consider new information more effectively, which leads to better learning. Furthermore, conceptual change needed for long-term learning requires that students construct appropriate mental representations as well as inhibit previously learned misconceptions (Dunbar \& Klahr, 2013; Fischler \& Lichtfeld, 1992). For instance, students must inhibit their prior misconceptions about the equal sign as an operator in mathematics to properly engage in reasoning and understanding of a new lesson on a mathematical equivalence that predicts long term algebraic knowledge (McNeil \& Alibali, 2005). 
Our findings are consistent with research on learning that implicates cognitive regulation as a critical factor predicting long term achievement (Claessens et al., 2009; Duncan et al., 2007; Watts, Duncan, Siegler \& Davis-Kean, 2014). They are also conceptually similar to those of Duncan and colleagues (2007), who used 6 longitudinal datasets to test socioemotional, cognitive, and school-entry skills that contribute most to long-term achievement, as assessed by teachers' reports, test scores, and grade retention in elementary. Across all 6 studies, cognitive skills, specifically attention skills, were one of the strongest predictors of long-term achievement. By contrast, measures of socioemotional behaviors, including social skills, were generally insignificant predictors of long-term academic achievement even after accounting for cognitive skills such as attention (Duncan et al., 2007). Examining cognitive skills separately from behavior problems suggests that cognitive skills predict later achievement differently compared to behavioral regulation (Barriga et al., 2002; Hinshaw, 1992; Konold \& Pianta, 2005; Trzesniewski et al., 2006). Our work here and elsewhere (Modrek et al., 2019) revealed that cognitive regulation and behavior regulation are indeed interrelated, but only cognitive regulation predicts inquiry learning, as assessed by the applied inductive reasoning activities in the task administered.

Nevertheless, some other studies have arrived at different conclusions. For instance, previous investigations have reported that behavioral measures of self-regulation (i.e., selfreported grit and teacher ratings) account for more variance in grades on report-cards 2-years into the future. Still, cognitive measures of self-regulation (i.e., working memory, fluid reasoning) account for more variance in standardized test scores (Duckworth et al., 2012). Although these studies reported that cognitive regulation might be both a direct and an indirect predictor of long-term standardized test achievement, our work is limited by not including a measure of students' classroom GPA. 
Some additional limitations of the current work also need to be mentioned; for instance, given time limitations, our assessment of self-regulation focused solely on cognitive and behavior regulation and did not encompass emotion regulation. Similarly, the behavior regulation instrument used may have been more appropriate for a state-based measure, given its assessment in a naturalistic setting (e.g., classroom learning environments). In contrast, the cognitive regulation task was more appropriate for a trait-based assessment. Additionally, we measured both cognitive and behavioral regulation once at the beginning of the year, which makes it impossible to determine how changes in the development of students' self-regulation skills affect standardized test performance. Additionally, both behavior and cognitive regulation are multidimensional constructs, and our assessments only encompass a small part of the skills that underlie these constructs (Sinatra et al., 2015). Our results, therefore, should be viewed as preliminary, and further investigation should evaluate the generalizability of the metrics administered.

In summary, our findings extend the existing literature by demonstrating that the selfregulatory skills of an effective learner may be different compared to those needed for an academic performer (Modrek \& Kuhn, 2017), especially for long-term achievement. Along with other research, our findings suggest that skills required for both learning and long-term academic achievement can potentially stem from a specific set of self-regulation skills, specifically cognitive regulation. Fortunately, research suggests that these skills can be developed (Diamond, 2012; Diamond et al., 2007; Schunk, 2005), and to this extent, our findings suggest that their development will contribute not only to long-term achievement but also to pathways that will foster effective learning skill on the way. 


\section{References}

Bailey, D., Duncan, G. J., Odgers, C. L., \& Yu, W. (2017). Persistence and fadeout in the impacts of child and adolescent interventions. Journal of research on educational effectiveness, 10(1), 7-39.

Bandura, A., Caprara, GV., Barbaranelli, C., Pastorelli, C., Regalia, C. (2001) Sociocognitive self-regulatory mechanisms governing transgressive behavior. Journal of Personality and Social Psychology, 80, 125-135. doi: 10.1037/0022-3514.80.1.125.

Barriga, A. Q., Doran, J. W., Newell, S. B., Morrison, E. M., Barbetti, V., \& Dean Robbins, B. (2002). Relationships between problem behaviors and academic achievement in adolescents: The unique role of attention problems. Journal of Emotional and Behavioral Disorders, 10(4), 233-240.

Baumeister, R. F., Heatherton, T. F., \& Tice, D. M. (1994). Losing control: How and why people fail at self-regulation. Academic Press.

Ben-Eliyahu, A., \& Linnenbrink-Garcia, L. (2015). Integrating the regulation of affect, behavior, and cognition into self-regulated learning paradigms among secondary and postsecondary students. Metacognition \& Learning, 10, 15 - 42.

Ben-Eliyahu, A. (2019). Academic Emotional Learning: A critical component of self-regulated learning in the emotional learning cycle. Educational Psychologist, 54(2), 84-105.

Blair, C., \& Diamond, A. (2008). Biological processes in prevention and intervention: The promotion of self-regulation as a means of preventing school failure. Development and Psychopathology, 20(3), 899.

Blair, C., Ursache, A., Greenberg, M., \& Vernon-Feagans, L. (2015). Multiple aspects of selfregulation uniquely predict mathematics but not letter-word knowledge in the early elementary grades. Developmental psychology, 51(4), 459.

Blair, C., \& Razza, R. P. (2007). Relating effortful control, executive function, and false belief understanding to emerging math and literacy ability in kindergarten. Child Development, 78(2), 647-663.

Blair, C., \& Raver, C. C. (2014). Closing the achievement gap through modification of neurocognitive and neuroendocrine function: Results from a cluster randomized controlled trial of an innovative approach to the education of children in kindergarten. PloS one, 9(11), e112393.

Braga, M., Paccagnella, M., and Pellizzari, M. (2014). Evaluating students' evaluations of professors. Econ. Educ. Rev. 41, 71-88. doi: 10.1016/j.econedurev.2014.04.002 
Brock, L. L., Rimm-Kaufman, S. E., Nathanson, L., \& Grimm, K. J. (2009). The contributions of 'hot' and 'cool' executive function to children's academic achievement, learningrelated behaviors, and engagement in kindergarten. Early Childhood Research Quarterly, 24(3), 337-349.

Brown, B. B. (2004). Adolescents' relationship with peers. In R. Lerner \& L. Steinberg (Eds.), Handbook of adolescent psychology (2 ${ }^{\text {nd }}$ ed., pp. 363-394). New York: Wiley.

Brown, B. B., \& Larson, J. (2009). Peer relationships in adolescence. In R. Lerner \& L. Steinberg (Eds.), Handbook of adolescent psychology (3rd ed., Vol. 2, pp. 74-103). New York: Wiley.

Bull, R., \& Scerif, G. (2001). Executive functioning as a predictor of children's mathematics ability: Inhibition, switching, and working memory. Developmental neuropsychology, 19(3), 273-293.

Burrage, M. S., Ponitz, C. C., McCready, E. A., Shah, P., Sims, B. C., Jewkes, A. M., \& Morrison, F. J. (2008). Age-and schooling-related effects on executive functions in young children: A natural experiment. Child Neuropsychology, 14(6), 510-524.

Carrell, S. E., \& West, J. E. (2010). Does professor quality matter? Evidence from random assignment of students to professors. Journal of Political Economy, 118(3), 409-432.

Carver, C. S., \& Scheier, M. F. (2004). Self-regulation of action and affect. Handbook of selfregulation: Research, theory, and applications (pp.13-39).

Cisler, J.M., Olatunji, B.O., Feldner, M.T. \& Forsyth, J.P. (2010) Emotion regulation and the anxiety disorders: An integrative review. Journal of Psychopathol Behav Assess, 32(1), 68-82.doi: 10.1007/s10862-009-9161-1.

Chafouleas, S. M., Briesch, A. M., Riley-Tillman, T. C., Christ, T. J., Black, A. C., \& Kilgus, S. P. (2010). An investigation of the generalizability and dependability of Direct Behavior Rating Single Item Scales (DBR-SIS) to measure academic engagement and disruptive behavior of middle school students. Journal of School Psychology, 48(3), 219-246.

Chevalier, N., Huber, K. L., Wiebe, S. A., \& Espy, K. A. (2013). Qualitative change in executive control during childhood and adulthood. Cognition, 128(1), 1-12.

Chinn, C. A., \& Malhotra, B. A. (2002). Epistemologically authentic inquiry in schools: A theoretical framework for evaluating inquiry tasks. Science Education, 86(2), 175218.

Claessens, A., Duncan, G.J., Engel, M. (2009) Kindergarten skills and fifth-grade achievement: Evidence from the ECLS-K. Economics of Education Review, 28, 415-427. 
Conway, A., Miller, A. L., \& Modrek, A. (2017). Testing reciprocal links between trouble getting to sleep and internalizing behavior problems, and bedtime resistance and externalizing behavior problems in toddlers. Child Psychiatry \& Human Development, 48(4), 678-689.

Corno, L., \& Mandinach, E. B. (1983). The role of cognitive engagement in classroom learning and motivation. Educational psychologist, 18(2), 88-108.

Corno, L., \& Rohrkemper, M. (1985). The intrinsic motivation to learn in classrooms. Research on motivation in education, 2, 53-90.

D'Mello, S., Dieterle, E., \& Duckworth, A. (2017). Advanced, analytic, automated (AAA) measurement of engagement during learning. Educational psychologist, 52(2), 104123.

Dean Jr, D., \& Kuhn, D. (2007). Direct instruction vs. discovery: The long view. Science Education, 91(3), 384-397.

De Jong, T., \& Van Joolingen, W. R. (1998). Scientific discovery learning with computer simulations of conceptual domains. Review of Educational Research, 68(2), 179-201.

Diamond, A. (2012). Activities and programs that improve children's executive functions. Current directions in psychological science, 21(5), 335-341.

Diamond, A., Barnett, W. S., Thomas, J., \& Munro, S. (2007). Preschool program improves cognitive control. Science, 318(5855), 1387-1388.

Doremus-Fitzwater, T. L., Varlinskaya, E. I., \& Spear, L. P. (2010). Motivational systems in adolescence: Possible implications for age differences in substance abuse and other risk-taking behaviors. Brain Cogn., 72, 114-123. doi: 10.1016/j.bandc.2009.08.008

Duckworth, A. L., \& Seligman, M. E. (2005). Self-discipline outdoes IQ in predicting academic performance of adolescents. Psychological science, 16(12), 939-944.

Duckworth, A. L., Tsukayama, E., \& Geier, A. (2010). Self-controlled children stay leaner in the transition to adolescence. Appetite, 54, 304-308. doi:10.1016/j.appet.2009.11.016

Duckworth, A. L., \& Kern, M. L. (2011). A meta-analysis of the convergent validity of selfcontrol measures. Journal of research in personality, 45(3), 259-268.

Duckworth, A. L., Quinn, P. D., \& Tsukayama, E. (2012). What no child left behind leaves behind: The roles of IQ and self-control in predicting standardized achievement test scores and report card grades. Journal of educational psychology, 104(2), 439. 
Duncan, G.J., Dowsett, C.J., Claessens, A., Magnuson, K., Huston, A.C., Klebanov, P., Pagani, L.S., Feinstein, L., Engel, M., Brooks-Gunn, J., \& Sexton, H. (2007). School readiness and later achievement. Developmental psychology, 43(6), 1428.

Eccles, J. S., Wigfield, A., Midgley, C., Reuman, D., Iver, D. M., \& Feldlaufer, H. (1993). Negative effects of traditional middle schools on students' motivation. The elementary school journal, 93(5), 553-574.

Espy, K. A. (1997). The shape school: Assessing executive function in preschool children. Developmental Neuropsychology, 13(4), 495-499.

Espy, K. A., Kaufmann, P. M., McDiarmid, M. D., \& Glisky, M. L. (1999). Executive functioning in preschool children: Performance on A-not-B and other delayed response format tasks. Brain and cognition, 41(2), 178-199.

Espy, K. A., Bull, R., Martin, J., \& Stroup, W. (2006). Measuring the development of executive control with the shape school. Psychological assessment, 18(4), 373.

Feldlaufer, H., Midgley, C., \& Eccles, J. S. (1988). Student, teacher, and observer perceptions of the classroom environment before and after the transition to junior high school. The Journal of Early Adolescence, 8(2), 133-156.

Frick, M. A., Bohlin, G., Hedqvist, M., \& Brocki, K. C. (2019). Temperament and cognitive regulation during the first 3 years of life as predictors of inattention and hyperactivity/impulsivity at 6 years. Journal of Attention Disorders, 23(11), 12911302.

Fischler, H., \& Lichtfeld, M. (1992). Modern physics and students' conceptions. International Journal of Science Education, 14, 181-190.

Fried, C. B. (2008). In-class laptop use and its effects on student learning. Computers \& Education, 50(3), 906-914. doi:10.1016/j.compedu.2006.09.006

Ganesalingam, K., Yeates, K. O., Taylor, H. G., Walz, N. C., Stancin, T., \& Wade, S. (2011). Executive functions and social competence in young children 6 months following traumatic brain injury. Neuropsychology, 25(4), 466.

Geldhof, G. J., Little, T. D., and Colombo, J. (2010). "Self-regulation across the lifespan," in The Handbook of Life-Span Development, Vol. 2. Social and Emotional Development, eds M. E. Lamb, and A. Freund (Vol. eds R. M. Lerner) (Hoboken, NJ: Wiley), 116-157.

Graham, S., \& Taylor, A. Z. (2014). An attributional approach to emotional life in the classroom. In R. Pekrun \& L. Linnenbrink-Garcia (Eds.), International handbook of emotions in education (pp. 96-119). New York, NY: Routledge

Greiff, S., Fischer, A., Wüstenberg, S., Sonnleitner, P., Brunner, M., \& Martin, R. (2013). A 
multitrait-multimethod study of assessment instruments for complex problem solving. Intelligence, 41(5), 579-596.

Gross, J. J. (1998). Antecedent-and response-focused emotion regulation: Divergent consequences for experience, expression, and physiology. Journal of personality and social psychology, 74(1), 224.

Gross, J. J. (2008). Emotion regulation. Handbook of emotions, 3(3), 497-513.

Hasher, L., Zacks, R. T., \& May, C. P. (1999) Inhibitory control, circadian arousal, and age. In D. Gopher \& A. Koriat (Eds.), Attention and performance XVII (pp. 653-675). MIT Press.

Heaton, R. K., Chelune, G. J., Talley, J. L., Kay, G. G., \& Curtiss, G. (1993). Wisconsin Card Sorting Test (WCST) manual: Revised and expanded. Psychological Assessment Resources (PAR).

Herman, J. L. (1992). What research tells us about good assessment. Educational Leadership, 49(8), 74-78.

Hinshaw, S. P. (1992). Academic underachievement, attention deficits, and aggression: Comorbidity and implications for intervention. Journal of consulting and clinical psychology, 60(6), 893.

Hofmann, W., Schmeichel, B. J., \& Baddeley, A. D. (2012). Executive functions and selfregulation. Trends in cognitive sciences, 16(3), 174-180.

Holland, J. H., Holyoak, K. J., Nisbett, R. E., \& Thagard, P. R. (1989). Induction: Processes of inference, learning, and discovery. MIT press.

Holyoak, K. J., \& Cheng, P. W. (2011). Causal learning and inference as a rational process: The new synthesis. Annual review of psychology, 62, 135-163.

Hooper, C. J., Luciana, M., Conklin, H. M., \& Yarger, R. S. (2004). Adolescents' performance on the Iowa Gambling Task: implications for the development of decision making and ventromedial prefrontal cortex. Developmental psychology, 40(6), 1148.

Jones, L. B., Rothbart, M. K., \& Posner, M. I. (2003). Development of executive attention in preschool children. Developmental Science, 6(5), 498-504.

Junco, R. (2012). In-class multitasking and academic performance. Computers in Human Behavior, 28(6), 2236-2243.

Kaplan, A., Middleton, M. J., Urdan, T., \& Midgley, C. (2002). Achievement goals and goal structures. In C. Midgley (Ed.), Goals, goal structures, and patterns of adaptive learning (pp. 21-55). Erlbaum. 
Kim, Y. E., Brady, A. C., \& Wolters, C. A. (2020). College students' regulation of cognition, motivation, behavior, and context: Distinct or overlapping processes? Learning and Individual Differences, 101872.

Kim, S., Nordling, J. K., Yoon, J. E., Boldt, L. J., \& Kochanska, G. (2013). Effortful control in "hot" and "cool" tasks differentially predicts children's behavior problems and academic performance. Journal of abnormal child psychology, 41(1), 43-56.

Klahr, D., \& Dunbar, K. (2013). Developmental differences in scientific discovery processes. In Complex information processing (pp. 129-164). Psychology Press.

Konold, T. R., \& Pianta, R. C. (2005). Empirically-derived, person-oriented patterns of school readiness in typically-developing children: Description and prediction to first-grade achievement. Applied Developmental Science, 9(4), 174-187.

Kornell, N., \& Hausman, H. (2016). Do the best teachers get the best ratings? Frontiers in psychology, 7, 570 .

Kuhn, D., Modrek, A. S., Sandoval, W. A. (2020). Teaching and Learning by Questioning. In L. Butler, S. Ronfard, \& K. Corriveau (Eds.) The Questioning Child: Insights from Psychology and Education (pp. 232-251). Cambridge, UK: Cambridge University Press.

Kuhn, D., \& Pease, M. (2008). What needs to develop in the development of inquiry skills? Cognition and Instruction, 26(4), 512-559.

Kuhn, D., \& Pease, M. (2009). The dual components of developing strategy use: Production and inhibition. In H. S. Waters \& W. Schneider (Eds.), Metacognition, strategy use, and instruction. New York: Guilford Press.

Kuhn, D., Ramsey, S., \& Arvidsson, T. S. (2015). Developing multivariable thinkers. Cognitive Development, 35, 92-110.

Laird, T., Shoup, R., \& Kuh, G. D. (2005). Measuring deep approaches to learning using the National Survey of Student Engagement. In Annual meeting of the Association for Institutional Research.

Laursen, B., \& Collins, W. A. (2009). Parent-child relationships during adolescence. In R. Lerner \& L. Steinberg (Eds.), Handbook of adolescent psychology $\left(3^{\text {rd }}\right.$ ed.). Wiley.

Latzman, R. D., Elkovitch, N., Young, J., \& Clark, L. A. (2010). The contribution of executive functioning to academic achievement among male adolescents. Journal of Clinical and Experimental Neuropsychology, 32(5), 455-462. 
Li, J., Pang, B., Zhang, B., and Du, H. (2011). Self-regulation: From basic theories to applications. J. Beijing Norm. Univ. 2011, 5-13. doi: 10.1190/1.3659042

Lindquist, S. I., \& McLean, J. P. (2011). Daydreaming and its correlates in an educational environment. Learning and Individual Differences, 21, 158-167.

Linnenbrink, E. A., \& Pintrich, P. R. (2000). Multiple pathways to learning and achievement: The role of goal orientation in fostering adaptive motivation, affect, and cognition. In C. Sansone \& J. M. Harackiewicz (Eds.), Intrinsic and extrinsic motivation: The search for optimal motivation and performance (p. 195-227). Academic Press.

McClelland, M., Geldhof, J., Morrison, F., Gestsdóttir, S., Cameron, C., Bowers, E., Duckworth, A., Little, T., \& Grammer, J. (2018). Self-regulation. In Handbook of life course health development (pp. 275-298). Springer, Cham.

McClelland, M. M., Morrison, F. J., \& Holmes, D. L. (2000). Children at risk for early academic problems: The role of learning-related social skills. Early childhood research quarterly, 15(3), 307-329.

McNeil, N. M., \& Alibali, M. W. (2005). Why won't you change your mind? Knowledge of operational patterns hinders learning and performance on equations. Child Development, 76(4), 883-899.

Meindl, P., Yu, A., Galla, B. M., Quirk, A., Haeck, C., Goyer, J. P., Lejuez, C.W., D’Mello, S.K., \& Duckworth, A. L. (2019). A brief behavioral measure of frustration tolerance predicts academic achievement immediately and two years later. Emotion, 19(6), 1081.

Milyavskaya, M., Berkman, E. T., \& De Ridder, D. T. (2019). The many faces of self-control: Tacit assumptions and recommendations to deal with them. Motivation Science, 5(1), 79.

Miyake, A., Friedman, N. P., Emerson, M. J., Witzki, A. H., Howerter, A., \& Wager, T. D. (2000). The unity and diversity of executive functions and their contributions to complex "frontal lobe" tasks: A latent variable analysis. Cognitive psychology, 41(1), 49-100.

Miyake, A., \& Friedman, N. P. (2012). The nature and organization of individual differences in executive functions: Four general conclusions. Current directions in psychological science, 21(1), 8-14.

Modrek, A.S. (in press) Accounting for cognitive costs: Can scientists be creative? Philosophical Psychology.

Modrek, A. S., \& Sandoval, W. A. (2020) Can autonomy play a role in causal reasoning? Cognitive Development, 54(C), 1-9. 
Modrek, A. S., Kuhn, D., Conway, A., Arvidsson, T. (2019) Cognitive regulation, not behavior regulation, predicts learning. Learning and Instruction, 60(C), 237-244.

Modrek, A., \& Kuhn, D. (2017). A cognitive cost of the need to achieve? Cognitive Development, 44, 12-20.

Moffett, L., \& Morrison, F. J. (2020). Off-task behavior in kindergarten: Relations to executive function and academic achievement. Journal of Educational Psychology, 112(5), 938-955.

Ocumpaugh, J., Baker, R., Gowda, S., Heffernan, N., \& Heffernan, C. (2014). Population validity for educational data mining: A case study in affect detection. British Journal of Educational Psychology, 45, 487-501.

Ocumpaugh, J., Baker, R. S., \& Rodrigo, M. M. T. (2012). Baker-Rodrigo Observation Method Protocol (BROMP) 1.0. Training Manual version 1.0. Teachers College, Columbia University.

Ocumpaugh, J., Baker, R. S., \& Rodrigo, M. M. T. (2015). Baker Rodrigo Ocumpaugh Monitoring Protocol (BROMP) 2.0 Technical and Training Manual. New York, NY and Manila, Philippines: Teachers College, Columbia University and Ateneo Laboratory for the Learning Sciences.

Ocumpaugh, J. (2012). Baker-Rodrigo observation method protocol (BROMP) 1.0. Training manual version 1.0. Baker-Rodrigo Observation Method Protocol (BROMP) 1.0. Training Manual version 1.0, Tech. Rep.

Osborne, J., Simon, S., \& Collins, S. (2003). Attitudes towards science: A review of the literature and its implications. International journal of science education, 25(9), 1049-1079.

Pintrich, P. R., \& Schunk, D. H. (2002). Motivation in education: Theory, research, and applications. Prentice Hall.

Ponitz, C. E. C., McClelland, M. M., Jewkes, A. M., Connor, C. M., Farris, C. L., \& Morrison, F. J. (2008). Touch your toes! Developing a direct measure of behavioral regulation in early childhood. Early Childhood Research Quarterly, 23(2), 141-158.

Prencipe, A., Kesek, A., Cohen, J., Lamm, C., Lewis, M. D., \& Zelazo, P. D. (2011). Development of hot and cool executive function during the transition to adolescence. Journal of experimental child psychology, 108(3), 621-637.

Risko, E. F., Anderson, N., Sarwal, A., Engelhardt, M., \& Kingstone, A. (2012). Everyday attention: Variation in mind wandering and memory in a lecture. Applied Cognitive Psychology, 26(2), 234- 242.

Sacks, P. (2000). Predictable losers in testing schemes. School Administrator, 57(11), 6-9. 
Sameroff, A. (2010). A unified theory of development: A dialectic integration of nature and nurture. Child Development, 81(1), 6-22.

Schauble, L. (1990). Belief revision in children: The role of prior knowledge and strategies for generating evidence. Journal of experimental child psychology, 49(1), 31-57.

Schunk, D. H. (2005). Commentary on self-regulation in school contexts. Learning and Instruction, 15(2), 173-177.

Shepard, L. (2000). The role of assessment in a learning culture. Educational Researcher, 29(7), 4-14.

Shepard, L. A., \& Smith, M. L. (1990). Synthesis of research on grade retention. Educational Leadership, 47(8), 84-88.

Shoda, Y., Mischel, W., \& Peake, P. K. (1990). Predicting adolescent cognitive and selfregulatory competencies from preschool delay of gratification: Identifying diagnostic conditions. Developmental psychology, 26(6), 978.

Sinatra, G. M., Heddy, B. C., \& Lombardi, D. (2015). The challenges of defining and measuring student engagement in science. Educational Psychologist, 50(1), 1-13.

Smith, M. L., \& Fey, P. (2000). Validity and accountability of high-stakes testing. Journal of Teacher Education, 51(5), 334-344.

Smith, E. N., Romero, C., Donovan, B., Herter, R., Paunesku, D., Cohen, G. L., . . Gross, J. J. (2018). Emotion theories and adolescent well-being: Results of an online intervention. Emotion, 18(6), 781-788.

Sobel, D. M., \& Munro, S. E. (2009). Domain generality and specificity in children's causal inference about ambiguous data. Developmental psychology, 45(2), 511.

Soderstrom, N. C., \& Bjork, R. A. (2015). Learning versus performance: An integrative review. Perspectives on Psychological Science, 10(2), 176-199.

Stroebe, W. (2016). Are most published social psychological findings false?. Journal of Experimental Social Psychology, 66, 134-144.

Sturman, D. A., \& Moghaddam, B. (2011). The neurobiology of adolescence: changes in brain architecture, functional dynamics, and behavioral tendencies. Neurosci. Biobehav. Rev. 35, 1704-1712. doi: 10.1016/j.neubiorev.2011.04.003

Trzesniewski, K. H., Moffitt, T. E., Caspi, A., Taylor, A., \& Maughan, B. (2006). Revisiting the association between reading achievement and antisocial behavior: New evidence of an environmental explanation from a twin study. Child Development, 77(1), 72-88. 
Unsworth, N., \& McMillan, B. D., Brewer, G. A., \& Spillers, G. J. (2012). Everyday attention failures: an individual differences investigation. Journal of Experimental Psychology: Learning, Memory and Cognition, 38(6), 1765-1772.

Watts, T.W., Duncan, G.J., Siegler, R.S. \& Davis-Kean, P.E. (2014). What's Past is Prologue: Relations Between Early Mathematics Knowledge and High School Achievement. Education Research, 43(7): 352-360.

Weiner, B. (1985). An attributional theory of achievement motivation and emotion. Psychological Review, 92(4), 548.

Willoughby, M., Kupersmidt, J., Voegler-Lee, M., \& Bryant, D. (2011). Contributions of hot and cool self-regulation to preschool disruptive behavior and academic achievement. Developmental Neuropsychology, 36(2), 162-180.

Wilson, C. D., Taylor, J. A., Kowalski, S. M., \& Carlson, J. (2010). The relative effects and equity of inquiry-based and commonplace science teaching on students' knowledge, reasoning, and argumentation. Journal of Research in Science Teaching: The Official Journal of the National Association for Research in Science Teaching, 47(3), 276301.

Wilson, T. D., \& Buttrick, N. R. (2016). New directions in social psychological interventions to improve academic achievement. Journal of Educational Psychology, 108(3), 392.

Wood, E., Zivcakova, L., Gentile, P., Archer, K., De Pasquale, D., \& Nosko, A. (2012). Examining the impact of off-task multi-tasking with technology on real-time classroom learning. Computers \& Education, 58(1), 365-374.

Xu, F., Han, Y., Sabbagh, M. A., Wang, T., Ren, X., \& Li, C. (2013). Developmental differences in the structure of executive function in middle childhood and adolescence. PloS one, $8(10)$, e 77770 .

Yunker, P. J., Yunker, J. A. (2003). Are student evaluations of teaching valid? Evidence from an analytical business core course. J. Educ. Bus. 78, 313-317. doi:

$10.1080 / 08832320309598619$

Zhou, Q., Chen, S. H., \& Main, A. (2012). Commonalities and differences in the research on children's effortful control and executive function: A call for an integrated model of self-regulation. Child development perspectives, 6(2).

Zimmerman, B. J. (2008). Investigating self-regulation and motivation: Historical background, methodological developments, and future prospects. American Educational Research Journal, 45, 166-183. doi: 10.3102/0002831207312909 


\section{Appendix}

Figure 1

Data Collection Timeline

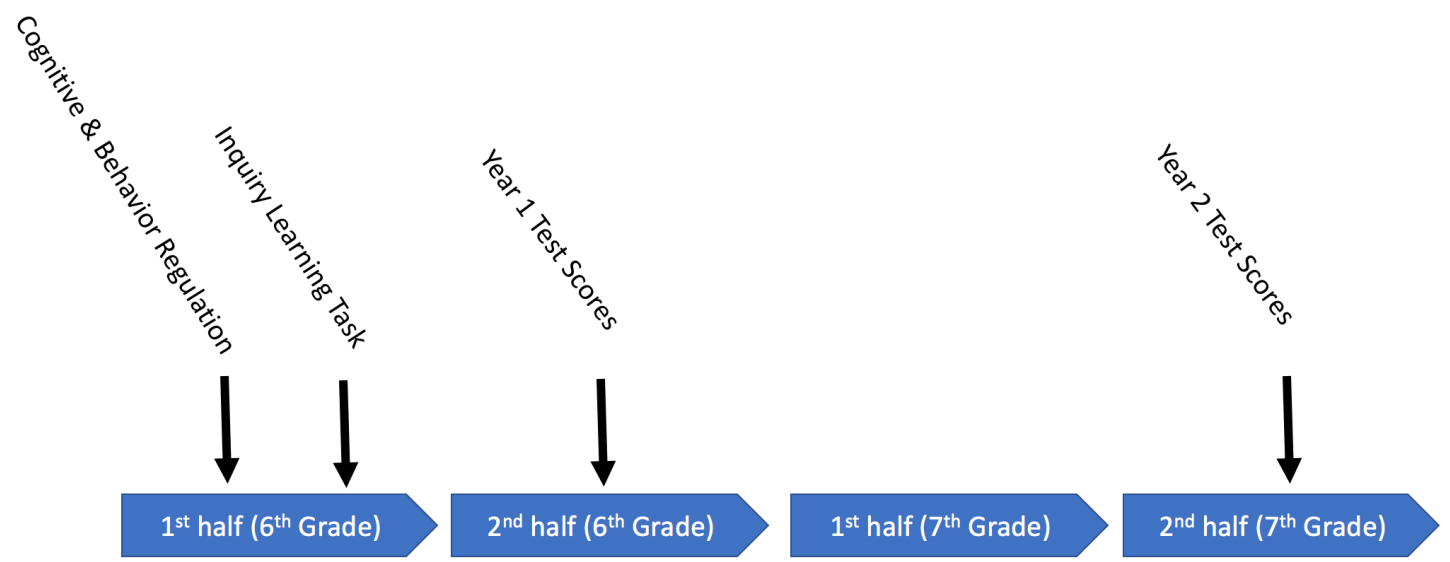


Figure 2

Structural Equation Model of Cognitive Regulation (Both; simultaneous inhibiting and switching), Inquiry Learning, and Long-Term Math Scores

(Standardized Solution; $n=127$ )

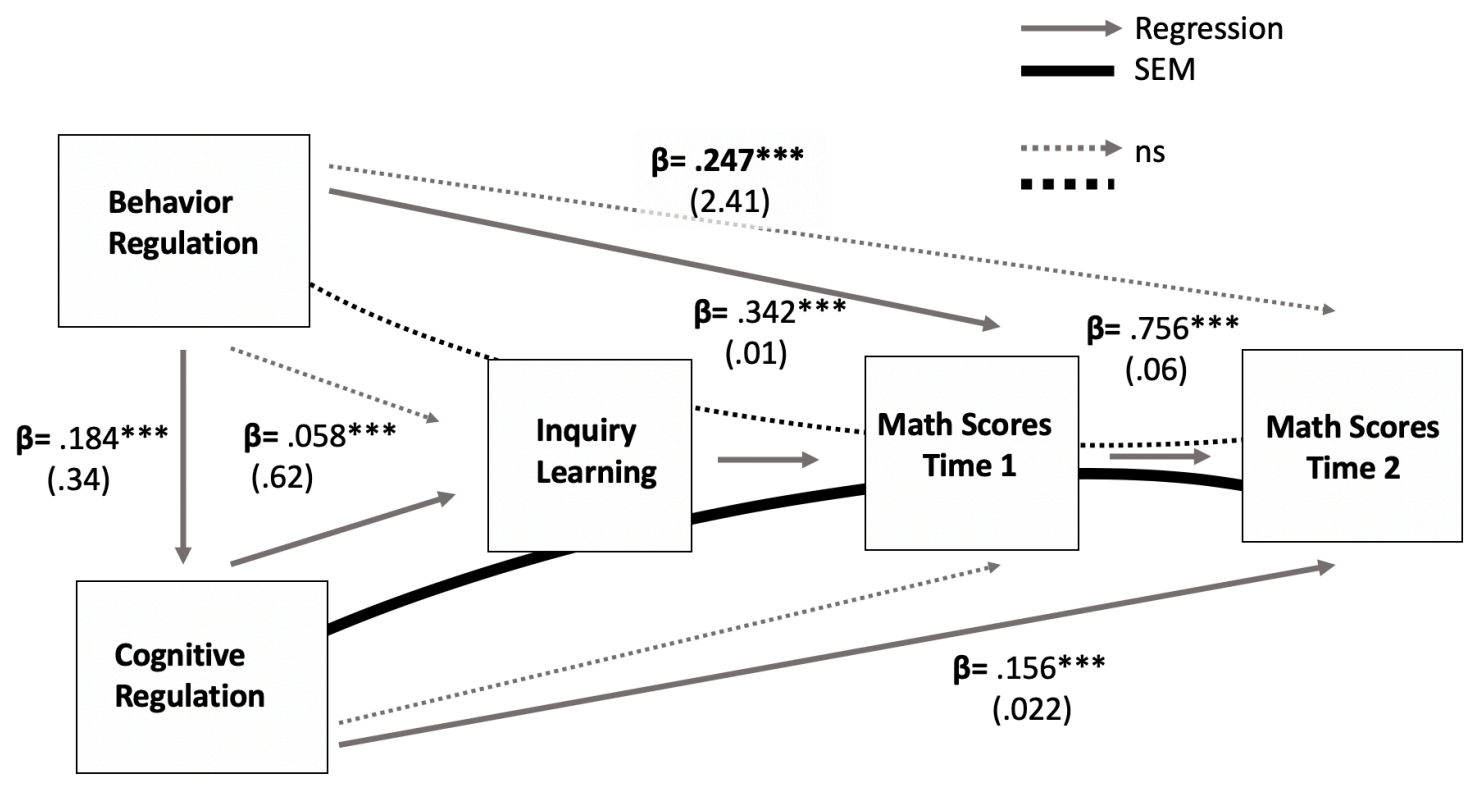

note: Individual regression betas reported above with standard error in parantheses. For SEM coefficients see

Table 1. Dashed line(s) highlight non-significant (ns) models. (Additional supplementary regression analyses can be found in supplementary results Tables S1, S2, and S3.)

*** Significant at the 0.001 level,

** Significant at the 0.01 level,

* Significant at the 0.05. 
Table 1

SEM: Cognitive Regulation (Both; simultaneous inhibiting and switching) predicting Inquiry Learning, and Long-Term Math Scores

Coefficient Standard $\quad \mathrm{p}>|\mathrm{z}| \quad 95 \% \mathrm{CI}$ Error

Inquiry Learning

\begin{tabular}{|c|c|c|c|c|}
\hline Cog Reg: Both & 1.770 & .622 & .004 & {$[.549,2.99]$} \\
\hline Age & 6.561 & 1.472 & .000 & {$[3.675,9.448]$} \\
\hline Sex & 1.463 & 1.910 & .443 & {$[-2.280,5.208]$} \\
\hline Bilingualism & -1.061 & 1.955 & .587 & {$[-4.893,2.771]$} \\
\hline constant & -21.148 & 17.035 & .214 & {$[-54.536,12.239]$} \\
\hline
\end{tabular}

Year 1 Math Score

\begin{tabular}{|c|c|c|c|c|}
\hline Inquiry Learning & .017 & .004 & .000 & {$[.008, .026]$} \\
\hline Cog Reg: Both & -.023 & .033 & .474 & {$[-.089, .041]$} \\
\hline Age & -.039 & .081 & .627 & {$[-.199, .120]$} \\
\hline Sex & -.113 & .098 & .252 & {$[-.306, .080]$} \\
\hline Bilingualism & .312 & .100 & .002 & {$[.116, .509]$} \\
\hline constant & 3.111 & .873 & .000 & {$[1.399,4.824]$} \\
\hline
\end{tabular}

Year 2 Math Score

\begin{tabular}{lrcccc}
\hline \multicolumn{1}{l}{ Year 1 Math Scores } & .691 & .055 & .000 & {$[.583, .799]$} \\
\hline Inquiry Learning & & .009 & .003 & .003 & {$[.003, .015]$} \\
\hline Cog Reg: Both & & .047 & .021 & .026 & {$[.005, .088]$} \\
\hline & Age & .062 & .052 & .235 & {$[-.040, .165]$} \\
\hline Sex & -.087 & .063 & .170 & {$[-.211, .037]$} \\
\hline Bilingualism & .077 & .066 & .244 & {$[-.052, .207]$} \\
\hline constant & -.424 & .590 & .472 & {$[-1.582, .733]$} \\
\hline
\end{tabular}

Note. Standardized solution; fit is acceptable 
Figure 3

Structural Equation Model of Cognitive Regulation (Both; simultaneous inhibiting and switching), Inquiry Learning, and Long-Term English Scores

(Standardized Solution; $n=127$ )

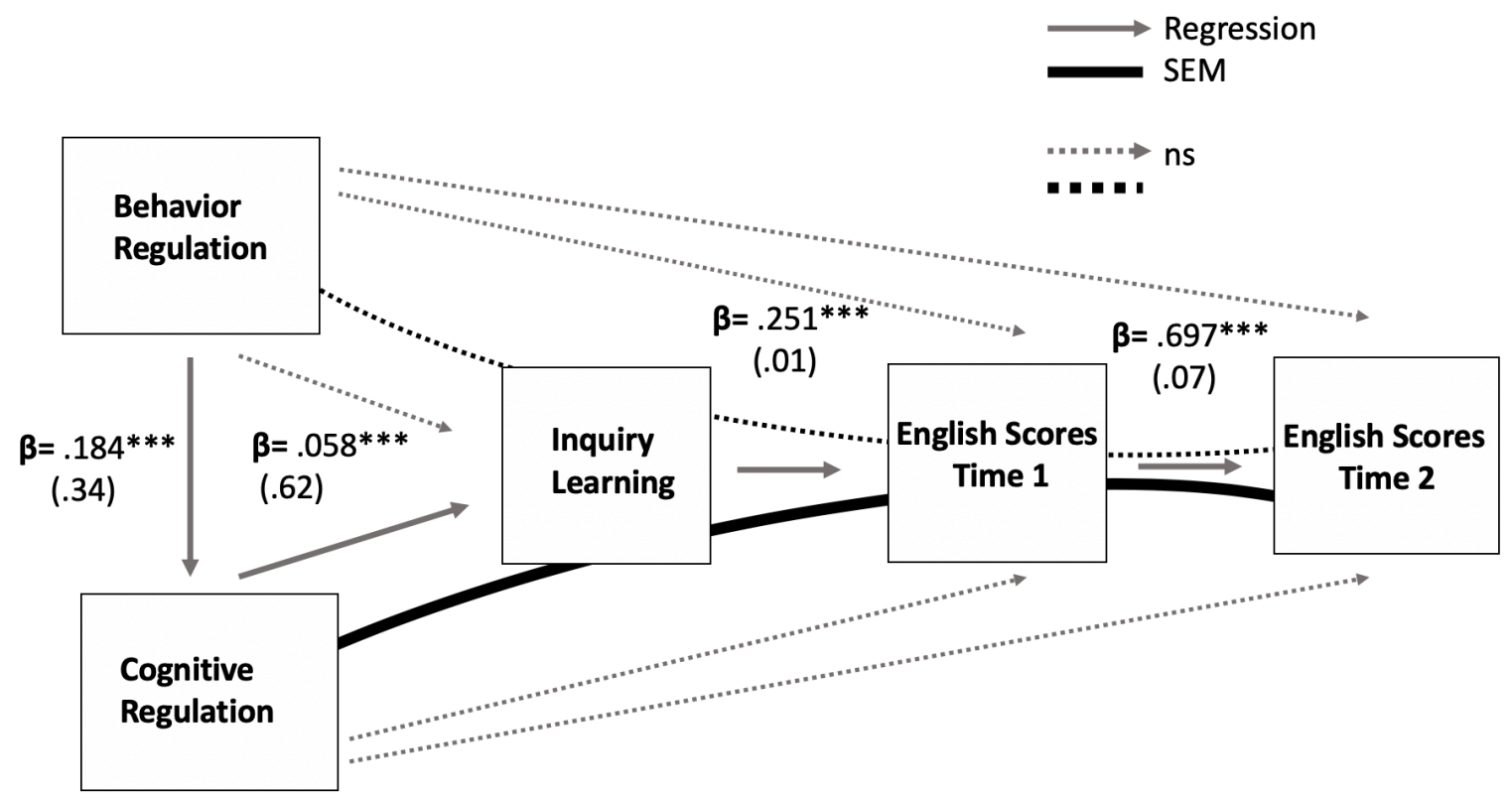

note: Individual regression betas reported above with standard error in parantheses. For SEM coefficients see

Table 2. Dashed line(s) highlight non-significant (ns) models. (Additional supplementary regression analyses can be found in supplementary results Tables S1, S2, and S3.)

*** Significant at the 0.001 level,

** Significant at the 0.01 level,

* Significant at the 0.05. 
Table 2

SEM: Cognitive Regulation (Both; simultaneous inhibiting and switching) predicting Inquiry Learning and Long-Term English Scores

Coefficient $\underset{\text { Error }}{\substack{\text { Standard } \\ \text { Erro }}} \quad \mathrm{p}>|\mathrm{z}| \quad 95 \% \mathrm{CI}$

\begin{tabular}{|c|c|c|c|c|c|}
\hline \multicolumn{6}{|l|}{ Inquiry Learning } \\
\hline Cog Reg: Both & & 1.808 & .622 & .004 & {$[.588,3.029]$} \\
\hline & Age & 6.749 & 1.474 & .000 & {$[3.859,9.639]$} \\
\hline & Sex & 1.333 & 1.911 & .485 & {$[-2.412,5.080]$} \\
\hline & Bilingualism & -.822 & 1.957 & .675 & {$[-4.659,3.015]$} \\
\hline & constant & -23.447 & 17.05 & .169 & {$[-56.877,9.982]$} \\
\hline
\end{tabular}

Year 1 English Test Score

\begin{tabular}{|c|c|c|c|c|}
\hline Inquiry Learning & .015 & .004 & .002 & {$[.005, .024]$} \\
\hline Cog Reg: Both & -.049 & .034 & .154 & {$[-.116, .018]$} \\
\hline Age & .094 & .084 & .266 & {$[-.071, .260]$} \\
\hline Sex & .309 & .102 & .002 & {$[.109, .509]$} \\
\hline Bilingualism & .099 & .103 & .336 & {$[-.103, .303]$} \\
\hline constant & 1.689 & .907 & .063 & {$[-.088,3.467]$} \\
\hline
\end{tabular}

Year 2 English Test Score

\begin{tabular}{lrcccc}
\hline \multicolumn{1}{l}{ Year 1 English Test Score } & & .661 & .065 & .000 & {$[.532, .789]$} \\
\hline Inquiry Learning & & .008 & .003 & .018 & {$[.001, .016]$} \\
\hline Cog Reg: Both & & .024 & .026 & .361 & {$[-.027, .075]$} \\
\hline & Age & .020 & .065 & .757 & {$[-.107, .147]$} \\
\hline Sex & -.041 & .080 & .603 & {$[-.198, .115]$} \\
\hline & Bilingualism & .059 & .079 & .453 & {$[-.095, .214]$} \\
\hline constant & .223 & .706 & .752 & {$[-1.161,1.607]$} \\
\hline
\end{tabular}

Note. Standardized solution; fit is acceptable. 


\section{Supplemental Results}

\section{Supplementary Tables}

As seen in Table S1, after including Year 1 test scores as a covariate, we generally find no direct association between the various components of behavior regulation and year 2 test scores for math or english. However, we did find a minor association between a subcomponent of behavior regulation and Year 2 english test scores (on-task behavior predicted long-term english test scores $B=.098, \mathrm{R}^{2}=.514(p<.05)$.

As seen in Table S2, after including Year 1 test scores as a covariate, some of the subcomponents of cognitive regulation predicted year 2 math test scores, but not year 2 english test scores.

As seen in Table S3, after including Year 1 test scores as a covariate, some of the subcomponents of inquiry learning continued to predict to both year 2 math test scores year 2 english test scores. 
Table S1. Behavior Regulation as a Predictor of Year 2 Standardized Test Performance

\begin{tabular}{|c|c|c|c|c|c|c|c|c|}
\hline \multirow[t]{2}{*}{ Behavior Regulation } & \multicolumn{4}{|c|}{$\begin{array}{c}\text { Year } 2 \text { Math } \\
\text { Standardized Test Scores }\end{array}$} & \multicolumn{4}{|c|}{$\begin{array}{c}\text { Year } 2 \text { English } \\
\text { Standardized Test Scores }\end{array}$} \\
\hline & $\mathrm{B}$ & $\mathrm{SE}(\mathrm{B})$ & $\beta$ & $\mathrm{R}^{2}$ & $\mathrm{~B}$ & $\mathrm{SE}(\mathrm{B})$ & $\beta$ & $\mathrm{R}^{2}$ \\
\hline On-Task Behavior & .047 & .020 & .004 & .603 & $.098 *$ & .041 & .152 & .514 \\
\hline Year 1 Scores & $.731 * * *$ & .060 & .745 & & $.694 * * *$ & .066 & .698 & \\
\hline On-Task Conversation & -.093 & .016 & -.020 & .619 & -.055 & .042 & -.085 & .498 \\
\hline Year 1 Scores & $.765^{* * *}$ & .059 & .747 & & $.690 * * *$ & .067 & .694 & \\
\hline Off-Task Behavior & .018 & .018 & .032 & .598 & -.030 & .041 & -.047 & .493 \\
\hline Year 1 Scores & $.756^{* * *}$ & .061 & .755 & & $.682 * * *$ & .067 & .687 & \\
\hline Behavior Regulation Total & -.017 & .009 & -.023 & .598 & .041 & .041 & .063 & .495 \\
\hline Year 1 Scores & $.755^{* * *}$ & .061 & .752 & & $684 * * *$ & .067 & .688 & \\
\hline
\end{tabular}


Table S2. Cognitive Regulation as a Predictor of Year 2 Standardized Test Performance

\begin{tabular}{|c|c|c|c|c|c|c|c|c|}
\hline \multirow[t]{2}{*}{ Cognitive Regulation } & \multicolumn{4}{|c|}{$\begin{array}{c}\text { Year } 2 \text { Math } \\
\text { Standardized Test Scores }\end{array}$} & \multicolumn{4}{|c|}{$\begin{array}{c}\text { Year } 2 \text { English } \\
\text { Standardized Test Scores }\end{array}$} \\
\hline & $\mathrm{B}$ & $\mathrm{SE}(\mathrm{B})$ & $\beta$ & $\mathrm{R}^{2}$ & $\mathrm{~B}$ & SE(B) & $\beta$ & $\mathrm{R}^{2}$ \\
\hline Inhibition & .015 & .049 & .017 & .614 & -.039 & .058 & -.042 & .500 \\
\hline Year 1 Scores & $.751 * * *$ & .057 & .755 & & $.698 * * *$ & .067 & .696 & \\
\hline Switching & .026 & .028 & .052 & .616 & -.015 & .033 & -.030 & .499 \\
\hline Year 1 Scores & $.750 * * *$ & .057 & .753 & & $.703 * * *$ & .067 & .701 & \\
\hline Both & $.063 * * *$ & .022 & .156 & .638 & .042 & .027 & .099 & .507 \\
\hline Year 1 Scores & $.749 * * *$ & .055 & .753 & & $.705 * * *$ & .066 & .703 & \\
\hline Cognitive Regulation Total & $.043 * * *$ & .016 & .149 & .635 & .008 & .019 & .025 & .498 \\
\hline Year 1 Scores & $.744 * * *$ & .055 & .748 & 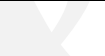 & $.699 * * *$ & .067 & .697 & \\
\hline
\end{tabular}


Table S3. Inquiry Learning as a Predictor of Year 2 Standardized Test Performance

\begin{tabular}{|c|c|c|c|c|c|c|c|}
\hline \multirow[t]{2}{*}{ Inquiry Learning } & \multicolumn{3}{|c|}{$\begin{array}{c}\text { Year } 2 \text { Math } \\
\text { Standardized Test Scores }\end{array}$} & \multicolumn{4}{|c|}{$\begin{array}{c}\text { Year } 2 \text { English } \\
\text { Standardized Test Scores }\end{array}$} \\
\hline & $\mathrm{SE}(\mathrm{B})$ & $\beta$ & $\mathrm{R}^{2}$ & $\mathrm{~B}$ & $\mathrm{SE}(\mathrm{B})$ & $\beta$ & $\mathrm{R}^{2}$ \\
\hline Inductive Learning .012*** & .004 & .205 & 629 & $.011 * *$ & .004 & .186 & .514 \\
\hline Year 1 Scores .691*** & .062 & .679 & & $.748 * * *$ & .060 & .745 & \\
\hline Application of Learning $\mathbf{. 0 4 9} * * *$ & .013 & .216 & .638 & .024 & .016 & .101 & .495 \\
\hline Year 1 Scores $.713^{* * *}$ & .059 & .701 & & $.684 * * *$ & .072 & .671 & \\
\hline Total Inquiry Learning $\mathbf{. 0 1 2} * * *$ & .003 & .230 & .637 & $.010 * *$ & .004 & .184 & .514 \\
\hline Year 1 Scores $.682 * * *$ & .061 & .671 & & $.659 * * *$ & .071 & .647 & \\
\hline
\end{tabular}




\section{Direct and Indirect Test Effects}

When testing direct and indirect effects for each path with estat teffects in STATA, a method commonly used after structural equation modeling (SEM) where z-scores and standard errors are obtained by the delta method (Sobel, 1987) we report that for math, there is (a) no direct effect between cognitive regulation (Both; inhibiting and switching) and math scores at Time $1,(\mathrm{z}=.26 ; p=.793)$, (b) there is a direct effect between cognitive regulation (Both; inhibiting and switching) and math scores at Time $2,(\mathrm{z}=2.24 ; p<.05),(\mathrm{c})$ there is a direct effect between behavior regulation and math scores at Time $1,(\mathrm{z}=3.45 ; p<.001)$, and (d) there is no direct effect between behavior regulation and math scores at Time $2,(\mathrm{z}=-0.38 ; p=.704)$.

Likewise, when testing the indirect effect, through learning, to math scores, we can again confirm that there is (e) an indirect effect between cognitive regulation (Both; inhibiting and switching) - through learning - to math scores $(\mathrm{z}=1.94 ; p<.05)$.

For english scores, we can again confirm that (f) there is no direct effect between cognitive regulation (Both; inhibiting and switching) and english scores at Time 1, $(\mathrm{z}=-0.99$; $p=.321),(\mathrm{g})$ there is also no direct effect between cognitive regulation (Both; inhibiting and switching) and english scores at Time $2,(\mathrm{z}=1.56 ; p=.118),(\mathrm{h})$ there is no direct effect between behavior regulation and english scores at Time $1,(\mathrm{z}=1.00 ; p=.320)$, and (i) there is no direct effect between behavior regulation and english scores at Time $2,(\mathrm{z}=.84 ; p=.403)$.

When testing indirect effects, through learning, to english scores, we can again confirm that there is $(\mathrm{j})$ an indirect effect between cognitive regulation (Both; inhibiting and switching) through learning - to english scores $(\mathrm{z}=2.02 ; p<.05)$. 